\title{
Research on the Current Situation and Countermeasures of Poverty Alleviation Driven by the TCM Industry in Hubei Province
}

\author{
Wu Hao-Qi ${ }^{1}$, Yan $\mathrm{Ni}^{1 *}$, Li Ling-Shan ${ }^{1}$, Cheng Xiao ${ }^{1}$ \\ ${ }^{1}$ School of Management, Hubei University of Chinese Medicine; Wuhan, China
}

\begin{abstract}
The year of 2020 is a decisive year for China to build a moderately prosperous society in all respects and fight against poverty. The traditional Chinese medicine (TCM) industry has become one of the main forms of poverty alleviation in China because of its functions of "making blood" and preventing poverty-returning phenomena. This study conducted a questionnaire survey and field interview on the situation of poverty alleviation driven by the TCM industry in Hubei Province from 2018 to 2019 to find out the problems of poverty alleviation in TCM industry and put forward corresponding countermeasures, so as to improve the long-term performance of poverty alleviation in TCM industry.
\end{abstract}

\section{Introduction}

Through the joint efforts on all sides in recent years, China has made remarkable progress in poverty alleviation. By the end of 2018, the rural poverty rate had dropped to 1.7 percent. However, when viewed at the micro-level, poverty reduction should focus not only on the quantity and scale, but also on the sustained quality. A series of poverty reduction practices in our country has proved that industrial poverty alleviation and health poverty alleviation will empower the poor households the means to prosper and prevent poverty-returning phenomena. Given the consideration of these two effects, traditional Chinese medicine (TCM) is the most commonly used form of poverty alleviation in China to bring high economic benefits of per unit, accelerate agricultural upgrading and improve the quality of the supply-side structural reform. However, due to its professionalism, ecological impact and a longer economic turnover cycle compared with ordinary agricultural products, poverty alleviation driven by Chinese medicine often requires continuous intellectual supports from the government, local enterprises, scientific research institutes and universities. While, health poverty alleviation driven by TCM is also confronted with problems like the shortage of professionals, limited medical conditions and strong reliance on polices. Generally speaking, the lack of sustainability is found in the current mode of poverty alleviation driven by the TCM industry.

In 2018 and 2019, this study conducted a sample survey on the distribution of TCM major industries in the cities and poverty-stricken counties in Hubei Province, mainly investigating the economic development of TCM industry, agriculture and commerce. It is aimed at finding out the problems in the process of poverty alleviation driven by TCM industry and putting forward the corresponding suggestions, thereby guiding the orderly, sound and sustainable development of TCM industry in poor regions to make sure it will help win the battle against poverty in all respects and make Chinese people accessible to the fruits of a moderately prosperous society on all fronts.

\section{CURRENT DEVELOPMENT OF TCM INDUSTRY IN HUBEI PROVINCE.}

\subsection{Industrial Advantages}

\subsubsection{A group of pharmaceutical enterprise brands developing based on natural and cultural resources}

Due to its rich natural resources of TCM, Hubei Province enjoys profound culture of TCM and a long-standing history of TCM industry. Among the 1,800-odd kinds of herbal medicines recorded in the Compendium of Materia Medica, there are more than 400 kinds in Wudang Mountain and 1,200 in Shennongjia. These two areas are extremely rich in the resources of genuine medicinal herbs and have more than 60 kinds of bulk medicinal herbs. The total number of genuine medicinal herbs in Hubei Province accounts for $20 \%$ of the total in China. So far, Hubei Province has great advantages in the production of genuine medicinal materials owing to its establishment of production bases and main producing areas. Hubei Province is in possession of a batch of famous pharmaceutical enterprises such as Mayinglong Pharmaceutical Group Co..Ltd. with a history of more than 400 years, Jianming Pharmaceutical Group Co.,Ltd. with a history of over 370 years and Zhonglian Pharmaceutical Group Co.,Ltd. with a history of more than 100 years. There are more than 1500 enterprises exclusively and partially engaged in Chinese medicine 
industry, including Chinese herbal pieces, Chinese patent medicine and health food products made of Chinese medicine. All of them have made important contributions to the medical and health undertakings and economic development in Hubei Province.

In recent years, the medical cultures originated from Li Shizhen and Shennong have been deeply explored and utilized in different regions. For example, Qichun County, relying on the cultural brand of $\mathrm{Li}$ Shizhen, has established a series of TCM R\&D, production and sales enterprises through continuous exploration and innovation. Among them, Li Shizhen Pharmaceutical Group has achieved outstanding results. Relying on Shennong culture, Fangxian County has established "Hubei Shennong Materia Medica Herbal Medicine Co.,Ltd.", Jiayu County has established "Hubei Shennong Pharmaceutical Co., Ltd.", etc., providing a good example for brand building.

\subsubsection{A well-established industry system consisting of TCM agriculture, industry, commerce and health service}

Hubei Province has diverse topography and unique climate, with Wuling Mountain area, Qinba Mountain area, Dabie Mountain area and Mufu Mountain area as the four main production areas of medicinal materials. It is known as the "Chinese Medicine Bank". According to the statistics, there are 246 enterprises producing (or additionally producing) Chinese herbal pieces, 337 enterprises producing (or additionally producing) Chinese patent medicine, 924 enterprises producing (or additionally producing) TCM health care products, and 50 provincial-level demonstration enterprises or bases for modernization of traditional Chinese medicine in Hubei Province. In 2018, the output value of the Chinese medicine industry reached 39.34 billion yuan, accounting for $33 \%$ of the province's pharmaceutical industry, with 6 of the enterprises entering the top 100 pharmaceutical companies in China. The enterprises all show a strong growth trend. There are a large number of traditional Chinese medicine retail enterprises in Hubei Province, which basically cover the main cities and counties, providing convenience for residents despite of the current environment of separation of hospitals and medicine.

\subsection{Problems and deficiencies}

The data collected from this field survey are as follows: 39 TCM agricultural enterprises and growers; 32 TCM industrial enterprises, including 6 enterprises producing Chinese herbal pieces, 7 enterprises producing TCM patent medicine and 19 enterprises producing TCM health care products; 84 typical TCM commercial enterprises, including 34 pharmaceutical circulation enterprises and 50 pharmaceutical sales enterprises. The survey data is shown in the figure below.
Table 1 Support needs of TCM agricultural enterprises surveyed

\begin{tabular}{|c|c|c|}
\hline Options & $\begin{array}{c}\text { Subtotal } \\
\text { (household) }\end{array}$ & Proportion \\
\hline Need policy support & 28 & $72.79 \%$ \\
\hline $\begin{array}{l}\text { Need both policy } \\
\text { support and technical } \\
\text { support }\end{array}$ & 16 & $41.02 \%$ \\
\hline $\begin{array}{c}\text { Need only policy } \\
\text { support }\end{array}$ & 12 & $30.77 \%$ \\
\hline $\begin{array}{l}\text { Need only technical } \\
\text { support }\end{array}$ & 2 & $5.12 \%$ \\
\hline $\begin{array}{c}\text { Missing Data or No } \\
\text { Need }\end{array}$ & 9 & $23.08 \%$ \\
\hline $\begin{array}{l}\text { Total enterprises } \\
\text { filled in this form }\end{array}$ & 39 & \\
\hline
\end{tabular}

Table 2 Difficulties faced by TCM industrial enterprises

\begin{tabular}{ccc}
\hline Options & $\begin{array}{c}\text { Subtotal } \\
\text { (household) }\end{array}$ & Proportion \\
\hline $\begin{array}{c}\text { Shortage of } \\
\text { professional talents } \\
\text { Insufficient funds } \\
\text { Insufficient } \\
\text { management } \\
\begin{array}{c}\text { experience } \\
\text { No corresponding } \\
\text { difficulties }\end{array}\end{array}$ M $^{\text {Missing Data }}$ & 6 & $29.03 \%$ \\
Total enterprises & 9 & $19.35 \%$ \\
filled in this form & 31 & $6.45 \%$ \\
\hline
\end{tabular}

Table 3 Policy and technical support needs of TCM industrial enterprises

\begin{tabular}{cll}
\hline Options & $\begin{array}{l}\text { Subtotal } \\
\text { (household) }\end{array}$ & Proportion \\
\hline $\begin{array}{c}\text { Need policy } \\
\text { support }\end{array}$ & 16 & $51.61 \%$ \\
$\begin{array}{c}\text { Need only } \\
\text { technical support }\end{array}$ & 7 & $22.58 \%$ \\
$\begin{array}{c}\text { Missing Data or } \\
\text { no need }\end{array}$ & 8 & $25.81 \%$ \\
$\begin{array}{c}\text { Total enterprises } \\
\text { filled in this form }\end{array}$ & 31 & \\
\hline
\end{tabular}

Table 4 Difficulties faced by the development of TCM commercial enterprises (multiple choices)

\begin{tabular}{ccc}
\hline Options & $\begin{array}{c}\text { Subtotal } \\
\text { (household) }\end{array}$ & Proportion \\
\hline $\begin{array}{c}\text { Technical difficulties } \\
\text { Talent shortage } \\
\text { Need financial } \\
\text { support }\end{array}$ & 16 & $39.02 \%$ \\
$\begin{array}{c}\text { Need policy support } \\
\text { Missing Data }\end{array}$ & 30 & $75.61 \%$ \\
$\begin{array}{c}\text { Total enterprises filled } \\
\text { in this form }\end{array}$ & 8 & $73.17 \%$ \\
\hline
\end{tabular}




\section{Countermeasures and suggestions on the poverty alleviation by developing TCM industry in Hubei Province}

\subsection{Giving full play to the supporting role of the government and strengthening the supervision mechanism}

To improve the efficiency of poverty alleviation in TCM industry and seize historic opportunities in targeted poverty alleviation, the government should provide supports in terms of policies, finances, technologies and talents based on resources and regional advantages of Hubei Province. The government needs to increase financial support for poverty alleviation in TCM industry. On the one hand, the investment threshold should be moderately reduced to encourage social capital and financial institutions to invest in poverty alleviation projects, and preferential policies and subsidized loans should be given to participating enterprises appropriately. In addition, the government should guide enterprises to participate in poverty alleviation projects and provide them with relevant policy supports and loan services, and give play to the leading role of leading enterprises. On the other hand, the relevant departments should actively cooperate and mobilize. The government needs to intensify information management and does a good job in publicity, providing a good policy environment for the poverty alleviation of TCM industry.

The government should also play a good supervisory role, strengthen the daily supervision of industrial poverty alleviation, rectify problems in a timely manner, standardize the use of project funds and ensure that they are earmarked for specified purposes. At the same time, the risk prevention mechanism should be improved and the investment and financing environment should be optimized to attract sound investments.

\subsection{Establishment of the long-term mechanism and optimization of the industrial development environment}

It is necessary to establish and improve the long-term mechanism of poverty alleviation of TCM industry. As an industry with a high degree of correlation, TCM's industrial structure covers all aspects from the cultivation of medicinal materials in the primary industry to the processing of TCM products in the secondary industry, and then to the medical services and cultural communication in the tertiary industry. We should establish the guarantee mechanism with all industrial chains interest for poor households, which organically associates poor households with industrial chains of TCM, transforms the buying and selling relationship between planters and enterprises into a joint-stock cooperative partnership. The poor households change from simply sharing the income by planting to the average profit of extensive participation in production and operation activities in all links of TCM industry, thus forming a long-term mechanism of interaction between poor households and enterprises to prevent them from returning to poverty.

The government should optimize the environment of industrial development. It needs to introduce the new mode of agricultural industrialization development characterized by "township of the specialty, leading enterprises, professional association and farmers", and encourage the cultivation of leading enterprises in agricultural industrialization so that farmers, enterprises and the government can form cooperative relations. TCM industry is assisted under the new thought of "substituting subsidies with awards, taking targeted policy for each household, driving by leading enterprises, adopting fallback guarantee", proving a favorable environment for the development of poverty alleviation projects in the TCM industry.

\subsection{Establishment of information service platform and improvement of TCM culture publicity}

Efforts should be made to promote the informationization construction of TCM enterprises in poor counties. With the pairing-assistance projects and supports from all sides, we should launch remote services, such as remote diagnosis, remote continuing education and remote guidance, to promote the effective sinking of high-quality TCM information and resources and to give services to local TCM enterprises and poor households. The government can assist enterprises and social institutions to jointly build information service platforms, and provide convenient channels for remote services and information gathering. At the meanwhile, it can work with schools to build online learning channels that provide farmers and self-employed households with access to remote education and remote guidance. To offer more information sources to farmers and enterprises, it is necessary to appropriately lower the threshold of Internet publicity, create diversified channels for the publicity of TCM culture, sort and release reports and information related to local competitive products through official accounts verified on WeChat, Weibo and other short-video platforms. At the same time, it is necessary to diversify the content of TCM culture, collect knowledge of TCM with local characteristics, enrich the propaganda content, and guide planters and enterprises to improve production efficiency with the help of relevant knowledge.

\subsection{Active introduction of professional talents and improvement of talent training mechanism}

In terms of the introduction of TCM talents, we should implement a flexible mechanism of talent recruitment and utilization. We should adopt an active, open and effective talent introduction policy based on campus recruitment and assisted by social recruitment to attract and pick over more excellent talents. One-stop services should be provided for high-level talents, including 
household registration, medical care, insurance, children's schooling, spouse's employment and other services. We should establish the dynamic management mechanism including talents' induction and resignation. The government should establish and improve the classified management for high-level talents, implement the dynamic management mode of "scientific management, classified evaluation, dynamic recruitment and mechanism support", and continue efforts to optimize the incentive mechanism of high-level talents.

With the enterprise as the leader, we need to provide technical training in planting, production, processing and R\&D. We should also establish cooperative mechanism, regularly provide lectures on relevant knowledge, give opportunities to talents on specific positions to go out for study, and constantly cultivate localized professional talents. Meanwhile, the government should establish cooperative relations with schools and large and medium-sized TCM enterprises, create activities such as academic exchanges, scientific research exchanges, study and visits, providing diversified options for local talent training.

\subsection{Establishment of supervision indicator system and adjustment of industrial development direction}

The government should establish the supervision indicator system that regularly sort the relevant data of poverty alleviation projects, master the overall situation of the cultivation of Chinese medicinal materials and the development of TCM industry, timely find out the problems and adjust the allocation of resources, so as to prevent the waste of resources caused by blind pursuit of large-scale production. The main indicators include input indicators and output indicators consisting of financial indicators, agricultural indicators and industrial indicators. Through this system, regulators can collect relevant data in a timely manner and analyze their relationship, timely find out the problems in production, as well as take into account the data of all parties to comprehensively evaluate the poverty alleviation efficiency of the TCM industry. Endowed with both traditional culture and natural advantages in poverty alleviation through its industry, TCM is one of the driving forces to win the battle against poverty. With the continuous attention of the CPC and the state, more and more people have gotten rid of poverty through the TCM industry and the poor population embraces greater confidence in lifting out of poverty and as well as in the better development of TCM.

\section{Reference}

1. Luo Zhonghua, Chang Jianqiao, Zhang Xiang. Problems and Countermeasures of Targeted Poverty Alleviation of Traditional Chinese Medicine in Gansu Province[J]. Journal of Traditional Chinese Medicine Management, 2019.10 (27) 5-8

2. Du Yuexin, Sun Tongquan, Pan Zhong. Problems and Countermeasures of traditional Chinese Medicine Industry Promoting Sustainable Poverty Alleviation and Rural Revitalization: Based on the Investigation of Traditional Chinese Medicine Planting Bases of Beijing Tongrentang in Pingjiang, Tongling and Minxian Counties[J]. China Development Observation, 2019 (6): 58-62

3. Lin Zeliang. Industrial Poverty Alleviation Mode and Innovation Analysis under the Background of Targeted Poverty Alleviation--Taking the Poverty Alleviation of Traditional Chinese Medicine Industry in Longxi County as an Example[J]. Guangdong University of Foreign Studies and Foreign Trade, 2018.6

4. Wang Huimin, Chen Yao and Nan Meihua. Research on the Construction of Long-term Mechanism for Poverty Alleviation of Traditional Chinese Medicine Industry in Guizhou Province[J]. Law-Based Society, 2019.5,179-180

5. Liu Jinhong, Zhong Ding, Liu Zhengyu, Xia Xinbin. Research on the Mode of Traditional Chinese Medicine Assisting Rural Revitalization[J]. Soft Science of Health, 2020.3 (34）27-31 